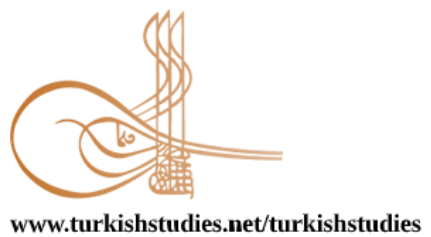

Turkish Studies

\title{
Koronavirüs (Covid-19) Salgınının Spor Organizasyonlarına Etkisi ve Sporda Normalleşme Süreci
}

\author{
The Effect of Coronavirus (Covid-19) Pandemic on Sports for Peer Review Only Organizations \\ and Normalization Process in Sport
}

\author{
Ali Gürel Göksel*
}

\begin{abstract}
The coronavirus, which started to be mentioned in the last days of 2019, spread rapidly all over the world at the beginning of 2020 and caused the death of more than 600 thousand people in parallel with the increase in the number of cases. With the World Health Organization making a pandemic decision, significant restrictions (stopping travels, interrupting education, social distance rule, cancellation of crowded organizations etc.) have been implemented in all countries. Considered the nature of the globalizing sports industry, there are relationship-based sports events that bring athletes together; it can be said that fans and media professionals will only serve to increase the potential threat to the spread of the disease. Postponing sports organizations are among these measures. The prolongation of the process caused the sports industry to start to shake economically, as in all sectors. This review study focuses on the effects of postponing or cancellation of large sports organizations due to the Covid-19 pandemic on the sports industry and possible financial consequences, the expectations of sports fans about the conditions that must be created in normalization process to decide participating sports events again even Covid-19 still exists. This study also provides several recommendations to individuals and officials who are in charge of organizing sports events. The fact that sports organizations will be launched within the framework of certain policies and rules will also add extra costs to sports clubs and federations. For this reason, all states should undertake some of the extra burdens on the clubs and federations by providing a little more economic support to the sports industry during this normalization process.
\end{abstract}

Structured Abstract: Rationale/Purpuse: The coronavirus, which started to be mentioned in the last days of 2019, spread rapidly all over the world at the beginning of 2020 and caused the death of more than 600 thousand people in parallel with the increase in the number of cases. With the World Health Organization making a pandemic decision, significant restrictions (stopping travels, interrupting education, social distance rule, cancellation of crowded organizations etc.) have been implemented in all countries. Postponing sports organizations are among these measures. The prolongation of the process caused the sports industry to start to shake economically, as in all sectors.

Design/methodology/approach: This study examined the literature with review approach.

Findings: This review study focuses on the effects of postponing or cancellation of large sports organizations due to the Covid-19 pandemic on the sports industry and possible financial consequences, the

\footnotetext{
* Doç. Dr., Muğla Sıtkı Koçman Üniversitesi, Spor Bilimleri Fakültesi, Spor Yöneticiliği Bölümü Assoc. Prof., Muğla Sitkı Koçman University, Faculty of Sport Sciences, Department of Sports Administration ORCID 0000-0002-3873-1322 gurelgoksel@gmail.com

Cite as/ Atıf: Göksel, A. G. (2020). Koronavirüs (Covid-19) salgınının spor organizasyonlarına etkisi ve sporda normalleşme süreci. Turkish Studies, 15(4), 451-462. https://dx.doi.org/10.7827/TurkishStudies.44314

Received/Geliș: 18 June/Haziran 2020

Accepted/Kabul: 10 August/Ağustos 2020

Checked by plagiarism software

Copyright $(\mathrm{C}$ MDE, Turkey 
expectations of sports fans about the conditions that must be created in normalization process to decide participating sports events again even Covid-19 still exists.

The Covid-19 outbreak is said to have devastating effects on the dynamics of all industries globally (Nicola et al., 2020), and this outbreak has unexpectedly caused significant constraints in all sectors of society, including sports. Over time, the speed of epidemic in the early days began to decline, although the Covid-19 pandemic did not have a complete cure or vaccine. This development increases the motivation of the business world, which experienced significant losses during the Covid-19 outbreak, to return to the old days. Undoubtedly, in this pandemic period in which social psychology is damaged due to restrictions, sports will have an essential contribution in starting the normalization process and gradually recovering old life, if not literally. Sports organizations and athletes will face complex decisions and practices in a wide variety of situations, from the resumption of training under the current conditions to the resumption of competitions.

Decisions on the timing of the resumption of sports and sports organizations should be consulted internationally to the World Health Organization and nationally to the Ministry of Health, and therefore government authorities, and decisions should be taken in line with their recommendations (Hughes et al., 2020). Persons and organizations in the position of decision-makers must carry out a risk assessment of the restart or cancellation of sports organizations; The social and economic consequences of decisions taken without this assessment can be both human and financially costly. In normalization of the sport again, the officials who will organize the sports events should ensure that this return does not endanger public health. However, it should be ensured that the health of athletes and all other personnel will not be compromised.

First, the general standards and minimum-security levels should be determined by considering the sports branches (team or individual) separately. However, since the economic strength of every sports branch is not the same within the sports industry, the decisions taken by a country regarding sports organizations differ. For example, the Turkish Basketball Federation (TBF, 2020) and the Turkish Volleyball Federation (TVF 2020) canceled all events happening during the summer of 2020 in consultation with Youth and Sports Ministry and by taking the ideas of the club. Turkish Football Federation (TFF, 2020a) decided to start the postponed leagues in June. Undoubtedly, although it is said that situations such as public health or athlete's health are considered in this decision, it is an indisputable fact that the economic health of the sponsor companies and other commercial relations with football clubs are taken into consideration. Because the participation money that will come from there is a continuation of the current order for that club, in particular, in low-income leagues like the Turkish league, the biggest aim of the clubs is to get the right to participate in the UEFA Champions League with sporting success.

For this reason, registering a league that has not been played for eight weeks will create a new chaos environment for a country that loves football. Therefore, TFF decided to play the last eight weeks by putting public health and athlete's health as a second plan. The explanation of TFF President Nihat Özdemir, "When the league starts, we will continue our way by separating the positive ones if there are positive cases in the teams" shows the determination to continue the league (BBC, 2020).

Consequently, Covid-19 pandemic has shaken commercial life all over the world. The sports industry and all its stakeholders have also faced substantial financial difficulties in a short period of 3 months from March 2020 to May 2020. Even if there is an expectation of normalization as soon as possible, it is a critical threat to public health, as watching sports in mass organizations, making trips can create a new Covid-19 wave. The fact that sports organizations will be launched within the framework of certain policies and rules will also add extra costs to sports clubs and federations. For this reason, all states should undertake some of the extra burdens on the clubs and federations by providing a little more economic support to the sports industry during this normalization process.

Practical Implications: This study also provides several recommendations to individuals and officials who are in charge of organizing sports events.

Research Contribution: This study contribute to sport management field with the recoomandations to continue sport organizations.

Keywords: Sports Organizations, Sports Industry, Coronavirus, Covid-19, Normalization Process. 
Öz: 2019 yılının son günlerinde adından söz ettirmeye başlayan koronavirüs, 2020 yılı ile birlikte tüm dünyada büyük bir hızla yayılmış ve vaka sayılarındaki artışa paralel olarak 600 binden fazla insanın ölümüne sebep olmuştur. Dünya Sağlık Örgütünün pandemi kararı almasıyla birlikte hemen hemen tüm ülkelerde önemli kısıtlamalara (seyahatlerin durdurulması, eğitime ara verilmesi, sosyal mesafe kuralı, kalabalık organizasyonların iptali vb.) gidilmiştir. Küreselleşen spor endüstrisinin doğası gereği sporcuları bir araya getiren ilişki temelli spor etkinlikleri olduğu düşünüldüğünde, taraftarlar ve medya çalışanları yalnızca Covid19 salgınının sürdürülebilir olmasına ve hastalığın yayılmasına yönelik potansiyel tehdidi artırmaya hizmet edeceği söylenebilir. Spor organizasyonlarının ertelenmesi de alınan bu önlemler arasındadır. Sürecin uzaması tüm sektörlerde olduğu gibi spor endüstrisinin de ekonomik anlamda sarsılmaya başlamasına sebep olmuştur. Tarama modeliyle yapılan bu nitel araştırmada, Covid-19 pandemisi sebebiyle büyük spor organizasyonlarının ertelenmesi veya iptal edilmesinin spor endüstrisindeki etkilerine ve olası finansal sonuçlarına, ayrıca sporda normalleşme sürecine ilişkin sporseverlerin yeniden spor etkinliklerine Covid-19 sırasında gitmeyi tercih etmeleri için oluşması gereken şartlara dair beklentilerinin neler olduğuna ve spor organizasyonlarını düzenlemede yetkili kişi ve kuruluşlara öneriler sunmaya odaklanılmıştır. Spor organizasyonların belirli politikalar ve kurallar çerçevesinde başlatılacak olması spor kulüplerine ve federasyonlara ekstra maliyetlerde doğuracaktır. Bu sebeple spor endüstrisine tüm devletlerin biraz daha ekonomik destek sağlayarak ve bu normalleşme sürecinde kulüplerin ve federasyonların üzerinde oluşacak fazladan yüklerin bir kısmını üstlenmesi gerekmektedir.

Anahtar Kelimeler: Spor Organizasyonları, Spor Endüstrisi, Koronavirüs, Covid-19, Normalleşme Süreci.

\section{Giriş}

2019 yılının son zamanlarında ilk kez Çin Halk Cumhuriyeti’nde görülen korona virüs hastalığ1 (Covid-19), 2020 y1lı ile birlikte etkisini hemen hemen tüm dünyada göstermeye başlamıştır. 12 Ocak 2020'de Dünya Sağlık Örgütü (WHO), Aralık 2019'da yeni bir korona virüs salgını sonrasında Çin Halk Cumhuriyeti'nin Hubei Eyaleti Wuhan'da 41 onaylanmış viral şiddetli akut solunum sendromu vakası olduğunu açıklamıştır (WHO, 2020c). Covid-19, insan etkileşimi yoluyla yüksek derecede bulaşıcı olan ciddi bir akut solunum sendromu olan koronavirüs-2'dir (SARS-CoV-2). Son zamanlarda Ebola ve SARS gibi diğer bulaşıcı hastalıkların benzer salgınlarından (Barabasi, 2015), sağlık ve siyasi otoriteler arasında pandemilere hazırlık ve küresel yayılma riskini azaltmanın önemli olduğu bilinmektedir. Spesifik bir tedavisi olmayan, ilacı veya aşısı bulunmayan ve küresel çapta büyük bir hızla yayılan ve sağlık sistemlerine büyük problemler yaratabilecek böylesine etkili bir hastalık için pandemi kararı almaktan başka bir çare kalmamıştır (Parnell, Widdop, Bond \& Wilson, 2020). Covid-19'un küresel çapta etki göstermeye başlaması ile Dünya Sağlık Örgütü'nün "Uluslararası Öneme Sahip Halk Sağlığı Acil Durumunu (Pandemi)” ilan etmesine yol açmıştır (WHO, 2020a). Korona virüsü kaynaklı Covid-19 hastalığı, 11 Mart tarihi itibarıyla Dünya Sağlık Örgütü tarafından pandemi ilan edildi. 11 Mart tarihinde yapılan açıklamaya göre, Corona virüsü salgını sebebiyle 114 ülkede 118 bin vakaya rastlandığı, 4 bin 291 kişinin ise hayatını kaybettiğinin açıklanmasının ardından DSÖ, Covid-19'un pandemik hastalıklar grubuna dahil edildiğini duyurmuştur.

Zaman geçtikçe küresel endişe ve birikmiş vakaların sayısı artmıştır (Hui, Madani, Ntoumi, Koch, \& Dar, 2020; Millán-Oñate ve ark., 2020; Rodríguez-Morales, MacGregor, Kanagarajah, Patel, \& Schlagenhauf, 2020; Wang, Horby, Hayden, \& Gao, 2020). Çoğu vaka anakara Çin'de olmasına rağmen, Dünyanın diğer bölgelerinde de her geçen gün artan vakalar ve ölümler rapor edilmiştir. $\mathrm{Bu}$ durum, beklendiği gibi Çin ve diğer ülkelerin halk sağlı̆̆ını ve ekonomisini bozmaktadır (Nishiura ve ark., 2020; Shigemura, Ursano, Morganstein, Kurosawa, \& Benedek, 2020).

Covid-19'un hızla yayılma potansiyeli ekstra önlemlerin alınması konusunda hükümetleri harekete geçirmiş ve yaşanan bu küresel endişe doğrultusunda, (Hellewell ve ark., 2020), eğitime arar verilmesine, seyahat yasaklarına (WHO, 2020a), sokağa çıkma kısıtlamalarına, toplumun bir 
arada zaman geçirdiği mekanların kapatılmasına ve dolayısıyla kitle halinde insanların toplanabilecekleri etkinlerin yapılmasının durdurulmasına karar verilmiştir (WHO, 2020b). Küresel yayılmayı en aza indirmek için doğru ve zamanında kararları alabilmek son derece önemlidir.

Memish ve arkadaşları (2019), ister müzikle ilgili bir gösteri ister dini bir organizasyon ister bir spor olayı olsun, insanların hep beraber oldukları kalabalık ve toplu organizasyonların şüphesiz bulaşıcı hastalıkların yayılmasına olumsuz anlamda katkıda bulunduğunu vurgulamıştır. Bu doğrultuda Covid-19 salgını zaman içinde Dünyadaki birçok büyük spor etkinliğinin de durdurulmasına, iptal edilmesine veya ertelenmesine sebep olmuştur (Clarkson, Culvin, Pope \& Parry, 2020). Tüm bunların sonucunda da hiç kuşku yok ki başta spor organizasyonlanı ve buna bağlı olarak spor kulüpleri ve sporcular ekonomik anlamda çok önemli kayıplar yaşamaktadırlar ve maalesef bir süre daha maddi sıkıntılar yaşayacakları öngörülmektedir.

$\mathrm{Bu}$ düşüncelerden hareketle araştırmada, Covid-19 pandemisi sebebiyle büyük spor organizasyonlarının ertelenmesi veya iptal edilmesinin spor endüstrisindeki etkilerine ve olas1 finansal sonuçlarına, ayrıca sporda normalleşme sürecine ilişkin sporseverlerin yeniden spor etkinliklerine Covid-19 sırasında gitmeyi tercih etmeleri için oluşması gereken şartlara dair beklentilerinin neler olduğuna ve spor organizasyonlarını düzenlemede yetkili kişi ve kuruluşlara öneriler sunmaya odaklanılmıştır.

\section{Covid-19 Salgını ve Spor Organizasyonlarına Etkisi}

Küreselleşen spor endüstrisinin doğası gereği sporcuları bir araya getiren ilişki temelli spor etkinlikleri olduğu düşünüldüğünde, taraftarlar ve medya çalışanları yalnızca Covid-19 salgınının sürdürülebilir olmasına ve hastalığın yayılmasına yönelik potansiyel tehdidi artırmaya hizmet edeceği söylenebilir.

Hükümetlerin spor organizasyonlarıyla ilgili verdikleri kararlar Covid-19 salgının ilk günlerinde çeşitli farklılıklar gösterse de ilerleyen zamanda tüm dünyada spor organizasyonlarına kilit vurulması gerektiği anlaşılmıştır. Bu gerçeğin farkında olan başta Dünya Sağlık Örgütü (WHO, 2011) ve hükümetler spor organizasyonlarını Şubat 2020'den itibaren farklı tarihlerde peşi sıra önce durdurma ve sonra Covid-19 salgınının seyrine göre nihai karar vermek üzere ileri bir tarihe erteleme kararı almışlardır.

$\mathrm{Bu}$ ertelemeler ile sadece yerel futbol liglerinin, basketbol, tenis müsabakalarından değil şu ana kadar 2020 Tokyo Olimpiyat Oyunları ve Avrupa Futbol Şampiyonas1 2020 (Euro 2020) gibi mega etkinliklerin bile bir yıldan fazla ertelenmesini içermektedir (Parnell ve ark., 2020). Dahas1, UEFA, IOC gibi organların Covid-19 salgınının ilk zamanlarındaki suskunluğuna rağmen, bu tür olayların ertelenmesi veya ertelenmesine ilişkin müteakip kararları (Evans ve ark., 2020) çeşitli paydaşların pozitifliği ile karşılanmıştır (Stevens \& Prins, 2020).

Dünyanın en büyük spor etkinliklerinden kabul edilen önemli spor organizasyonları 2020'de yapılması yıllar önceden planlandığı için Covid-19 salgını bu spor organizasyonları ve programları üzerinde maalesef olumsuz etkiler yaratmıştır. Futbolun milli takımlar düzeyinde Dünya Kupasından sonra en çok beklenen spor organizasyonu olan Euro 2020 turnuvasının düzenleyen Avrupa Futbol Federasyonları Birliği (UEFA) 17.Mart.2020 tarihinde, üye ülke federasyonlarının tamamının onayı ile turnuvayı 2021 yılına ertelenmiştir. Uluslararası Olimpiyat Komitesi (IOC) bu yaz düzenlenecek olan Tokyo 2020 Olimpiyatlarını 24.Mart.2020 tarihinde bir sonraki seneye ertelemeye karar vermiştir. Kaçınılmaz olarak, bu spor organizasyonlarının ertelenmesinin ortaya çıkaracağı maddi kayıplarının ağırlığı henüz gün yüzüne çıkmayan önemli bir mali yük yaratacaktır (Türkmen ve Özsar1, 2020). 
Grafik-1: Mayıs 2020 İtibariyle Covid-19 Salgını Nedeniyle Spor Endüstrisinde Yaşanan Gelir Kayb1

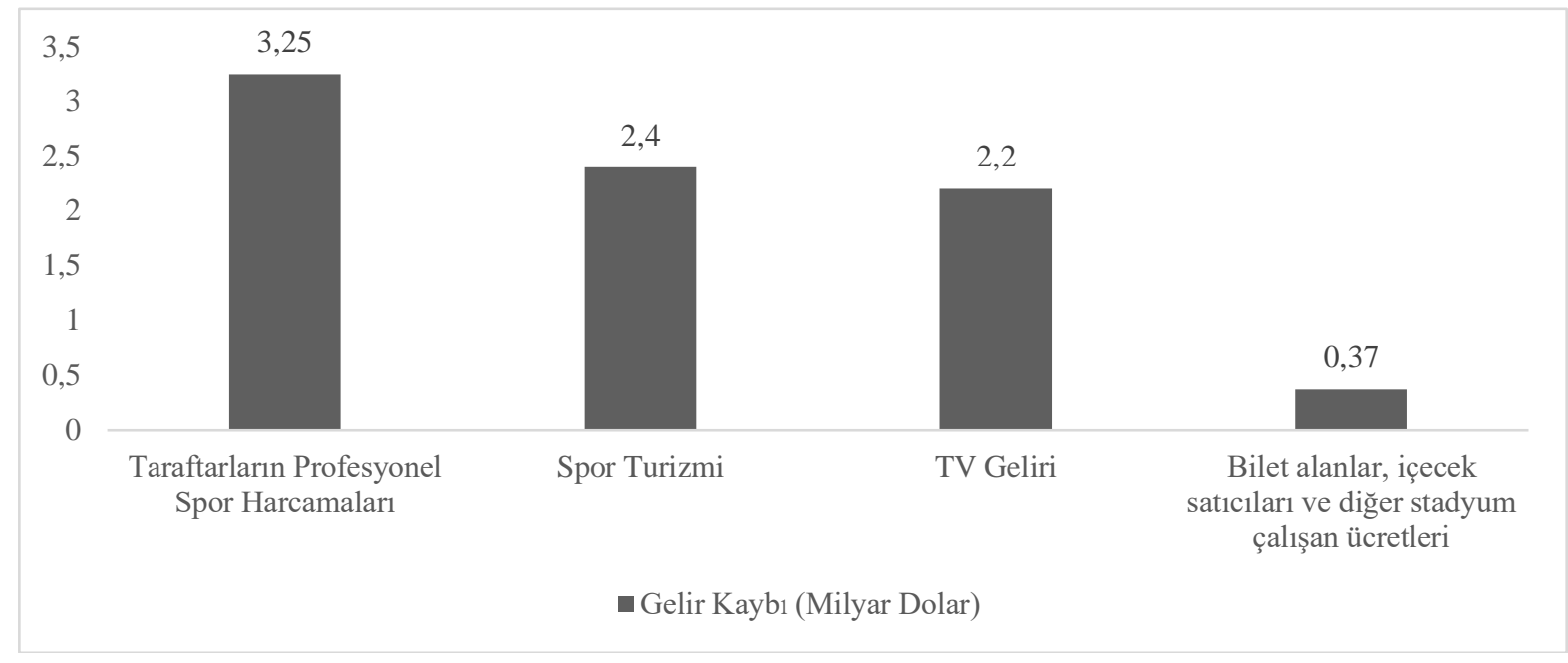

Kaynak: (Gough, 2020d)

Mayıs 2020 itibariyle Covid-19 salgını, tüm sektörlerde olduğu gibi, spor endüstrisini de ekonomik anlamda çok olumsuz etkilemiştir. Dünyanın dört bir yanındaki birçok profesyonel lig sezonlarını askıya aldı ve halka açık spor etkinlikleri iptal edildiğinden yüz binlerce kişi işsizlik sorunu ile yüz yüze kalmıştır. Analizler, Covid-19 salgını dolayısıyla spor organizasyonlarının ertelemeleri ve iptalleri sonucunda tahmini spor turizmi açısından gelir kaybının 2,4 milyar ABD doları olacağını gösterirken, ayrıca televizyon yayın gelirlerinden de 2,2 milyar ABD doları kriz sonucu gelir kaybının yaşanabileceği sonucunu gözler önüne sermektedir.

Grafik-2: 2019/2020 Sezonunda Covid-19 Nedeniyle Avrupa Futbol Liglerinin Potansiyel Maksimum Gelir Kayb1

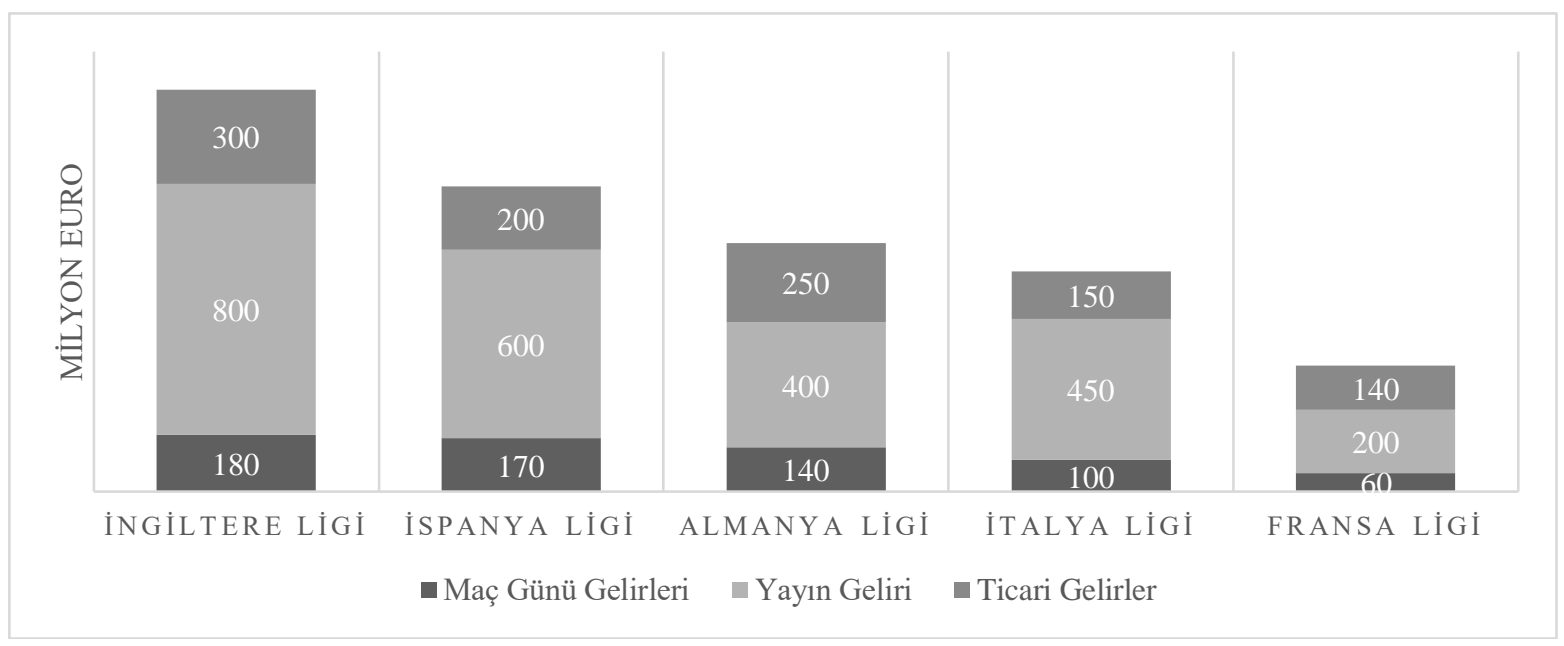

Kaynak: (Lagne, 2020)

Grafik-2'de görüldüğü üzere, 2019/2020 sezonunda ortaya çıkan Covid-19 salgını nedeniyle sadece İngiltere Premier Ligi'nin yaşayacağı gelir kaybının yaklaşık 1.280 milyon Euro olduğu tahmin edilmektedir. Avrupa futbolunun en önde gelen 5 liginde de en yüksek maddi kaybın yayın gelirlerinden olacağı öngörülmektedir. Araştırmaya konu olan bu 5 büyük Avrupa futbol liglerindeki toplam tahmini gelir kaybı ise yaklaşık 4 milyar Euro'nun üzerinde olacağı beklenmektedir. 
Spor organizasyonlarının Covid-19 pandemisi sebebiyle askıya alınması ve yaşanan belirsizlik sürecinde yaşanan ekonomik kayıplar sadece ligler özelinde yaşanmamaktadır. Bu liglerin marka değerlerini oluşturan ve arttıran futbol kulüpleri de büyük mali zorluklar içerinde kalmaktadır. Müsabakalara verilen arada planlanan müsabaka günü gelirleri, ticari gelirleri, yayın gelirleri vb. gelirleri sekteye uğrayan kulüpler nakit akışı sıkıntısı yaşamaya başlamış ve sporcularının maaşlarını ödemekte zorluk çekmeye başlamıştır. Özellikle sezon sonu sözleşmesi bitecek olan futbolcuların durumu ve onların kontratları önemli bir tartışma konusu haline gelmektedir. Öyle ki maçların yaz aylarında tekrar başlaması halinde bazı Avrupa kulüplerindeki futbolcuların serbest statüye geçecek olması ve kulüplerin sezonun geri kalanında bu futbolculardan yararlanamama durumu gün yüzüne çıkmıştır. Bu durumla ilgili olarak kulüpler en üst merci olan Uluslararası Futbol Federasyonları Birliği'nin (FIFA) kararını beklemektedir. Şu anki durumun devam etmesi halinde Haziran 2020 sonunda oyuncuları serbest kalacağı için futbolcu değeri açısından ligleri devam ederken en fazla değer kaybı yaşayacak futbol kulüpleri aşağıda görülmektedir.

Grafik-3: Covid-19 Pandemisine Bağlı Olarak 5 Büyük Avrupa Futbol Liginde Oyuncu Transfer Değerinin En Yüksek Yüzde Kaybı Yaşayacak İlk 10 Kulüp

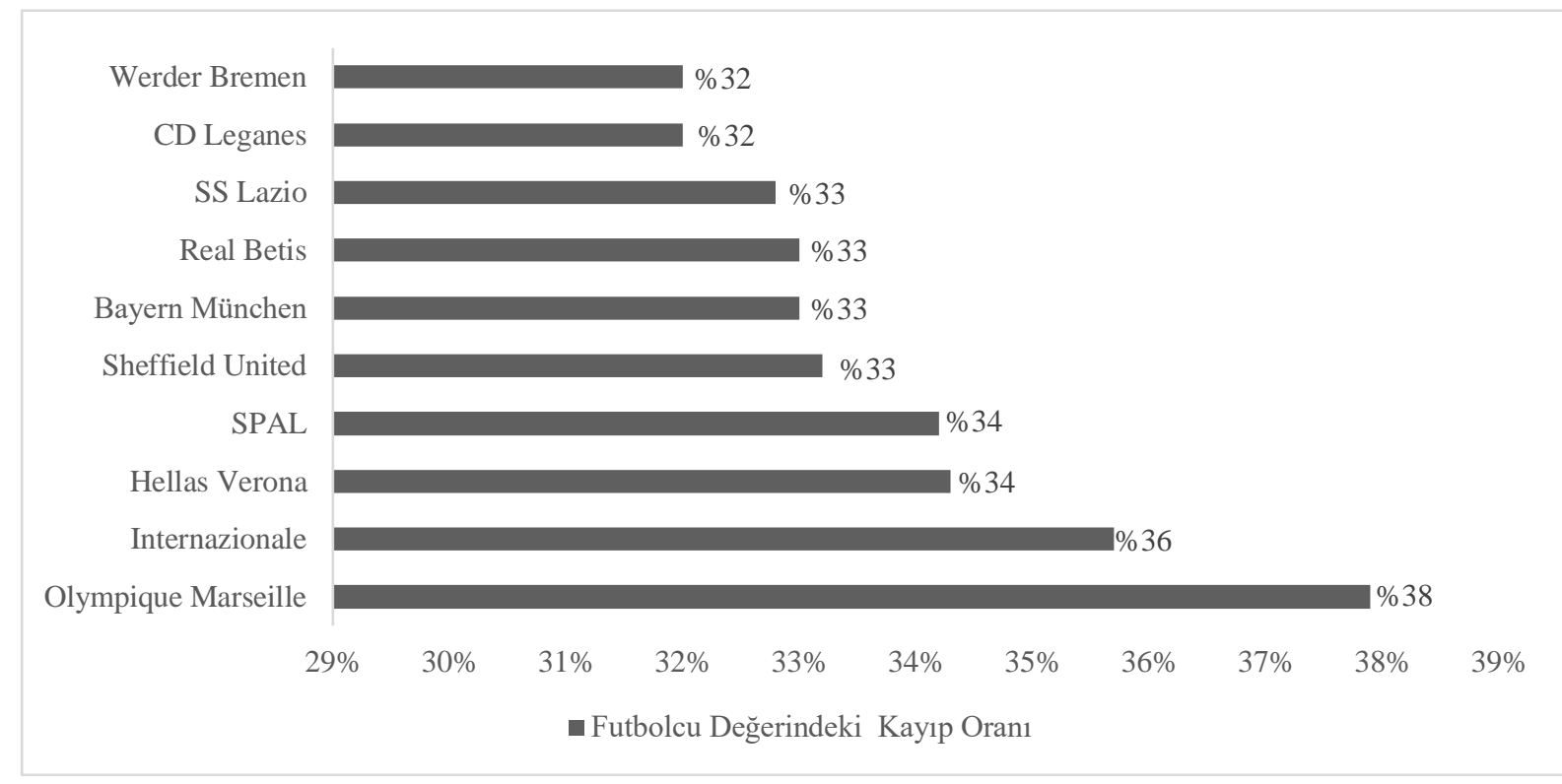

Kaynak: (Gough, 2020c)

Dünyanın dört bir yanındaki profesyonel futbol ligleri sezonlarının geri kalanını Covid-19 salgını sebebiyle askıya alarak işleyen ekonomik düzenlerini ve özellikle Avrupa futbol pazarını sorunlarla baş başa bıraktı. Bazı oyuncuların sözleşmelerinin sezon sonunda bitmesi ve futbol sezonunun bir sonuca varılıp oynanmayacağına dair henüz bir karar verilmemesinden dolayı, oyuncu transferleri ve sözleşmeleri hakkında büyük soru işaretleri yaşanmaktadır. Bu sezon daha fazla maç oynanmaması ve hiçbir kontratın Haziran 2020'den sonraya uzatılmaması durumunda, Fransa Ligue1 'de mücadele eden Olimpik Marsilya kulübü mevcut oyuncularının transfer değerinin \%38'ini kaybedecektir. Diğer en yüksek dokuz futbol kulübünün olası transfer değer kayıplarını Grafik-3'de görülmektedir.

\section{Sporda Covid-19 Salgını Sonrası Normalleşme Süreci}

Covid-19 salgını başlangıcından bu yana dünyanın neredeyse tüm ülkelerine yayılmıştır. Hastalığın yayılmasını engellemek için yaygın hale gelen sosyal ve fiziksel mesafeli önlemler, işletmelerin, okulların ve genel sosyal yaşamın kilitlenmesine, dolayısıyla da spor ve fiziksel aktivite de dahil olmak üzere yaşamın birçok düzenli yönünü olumsuz anlamda etkilemektedir (Caner ve 
ark., 2020; Güzel, Yildiz, Esentas, \& Zerengök, 2020). Spor endüstrisi, ülkelerin ekonomik ve sosyal kalkınmalarına oldukça büyük katkı vermektedir. Bunun farkında olan hükümetler ve diğer paydaşların yanı sıra Birleşmiş Milletler spor organizasyonlarının pandemi sırasında güvenli bir şekilde yeniden başlatılmasının yolları aranmakta ve bu spor organizasyonlarını desteklemek için öneriler sunulmaktadır.

Spor organizasyonunu düzenleyen kurum ve kuruluşlar açısından bakıldığında da Covid-19 salgınının devam ettiği süre içerisinde spor müsabakalarını öncelikle seyircisiz olarak başlatmak en önemli kısa vadeli çözüm olarak görülmektedir (TFF, 2020). Bu doğrultuda da Avrupa'da birçok ulusal futbol liglerin, özellikle UEFA'nın tavsiye kararları doğrultusunda (UEFA, 2020), Haziran 2020 aylarında kapalı kapılar ardında seyircisiz ve sınırlı sayıda sporcu, basın mensubu ve kulüp yetkililerinin alımı ile oynatılması planlanmaktadır.

Özellikle Avrupa'daki spor endüstrisinde en önemli paya sahip olan ve birçok sponsoru ve şirketleri peşinden sürükleyen futbolun tamamen seyircisiz oynanması uzun vadede çok olası gözükmemektedir. Bu sebepten dolayı hemen yaz aylarında olmasa bile, yeni sezonların olas1 başlayacağı güz aylarında kontrollü olarak seyirciye açılarak futbol müsabakalarının başlatılacağı düşünülebilir. Böyle bir durumda Covid-19 salgınının tüm dünyada tam anlamıyla sıfırlanmadığ 1 düşünüldügünde spor severleri tekrar stadyumlara çekmek spor organizatörleri açısından hiçte kolay olmayacaktır. Sporseverlerin kendilerini salgın sürecinde de güvende hissetmeleri ve stadyumlara gelerek canlı bir şekilde bizzat spor müsabakalarını yerinde izlemelerini ikna etmek için bir dizi tedbirlerin alınması gerekecektir.

Grafik-4: Sporseverlerin Covid-19 Sırasında Bir Spor Organizasyonuna Katılım Göstermeleri İçin Olması Gereken Koşullar

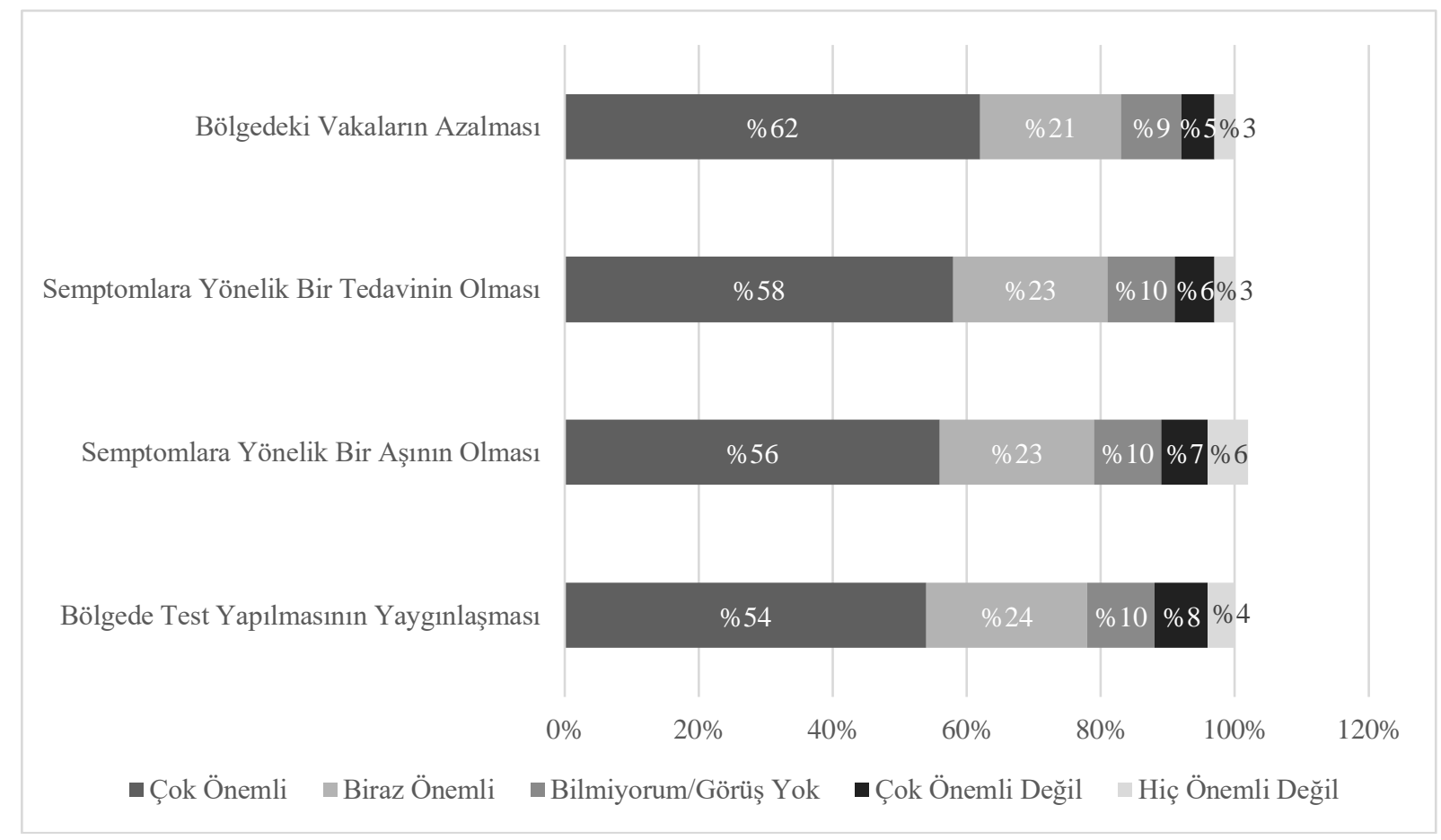

Kaynak: (Gough, 2020b)

Spor endüstrisinin en önemli aktörü olan tüketicileri yani sporseverleri spor organizasyonlarını talep etmeye devam etmeleri bu sektör için çok önemlidir. Amerika Birleşik Devletleri'nde 24-26.Nisan.2020 tarihleri arasında 2200 gönüllü 18 yaş ve üzeri bireyin katılımıyla gerçekleştirilen bir ankette, "Kalabalık bir spor etkinliğine katılmadan önce yukarıdaki maddelerin 
her birinin gerçekleşmesi ne kadar önemli?" sorusuna verecekleri cevap araştırılmıştır. Grafik-4'de görüldüğ̈̈ üzere sporseverlerin bir spor organizasyonunu bizzat yerinden çıplak gözle takip etmesi için Covid-19 salgınıyla ilgili hem bölgesel bazda hem de uluslararası düzeyde çözümlerin geliştirilmiş olması gerektiği anlaşılmaktadır.

Ayrıca Nisan 2020'de yapılan araştırmada "Covid-19 salgını kontrol altına alındıktan sonra bir stadyumda veya salonda bir spor etkinliğine katılırken aşağıdaki önlemlerden hangileri sizi daha rahat ve güvende hissettirir?" sorusu sorulmuş ve katılım gösteren sporseverlerden Grafik-5'teki sonuçlara ulaşılmıştır.

Grafik-5: Taraftarların Covid-19 Salgını Sirasında Bir Spor Organizasyonuna Katılımında Kendilerini Rahat Hissettirecek Önlemler

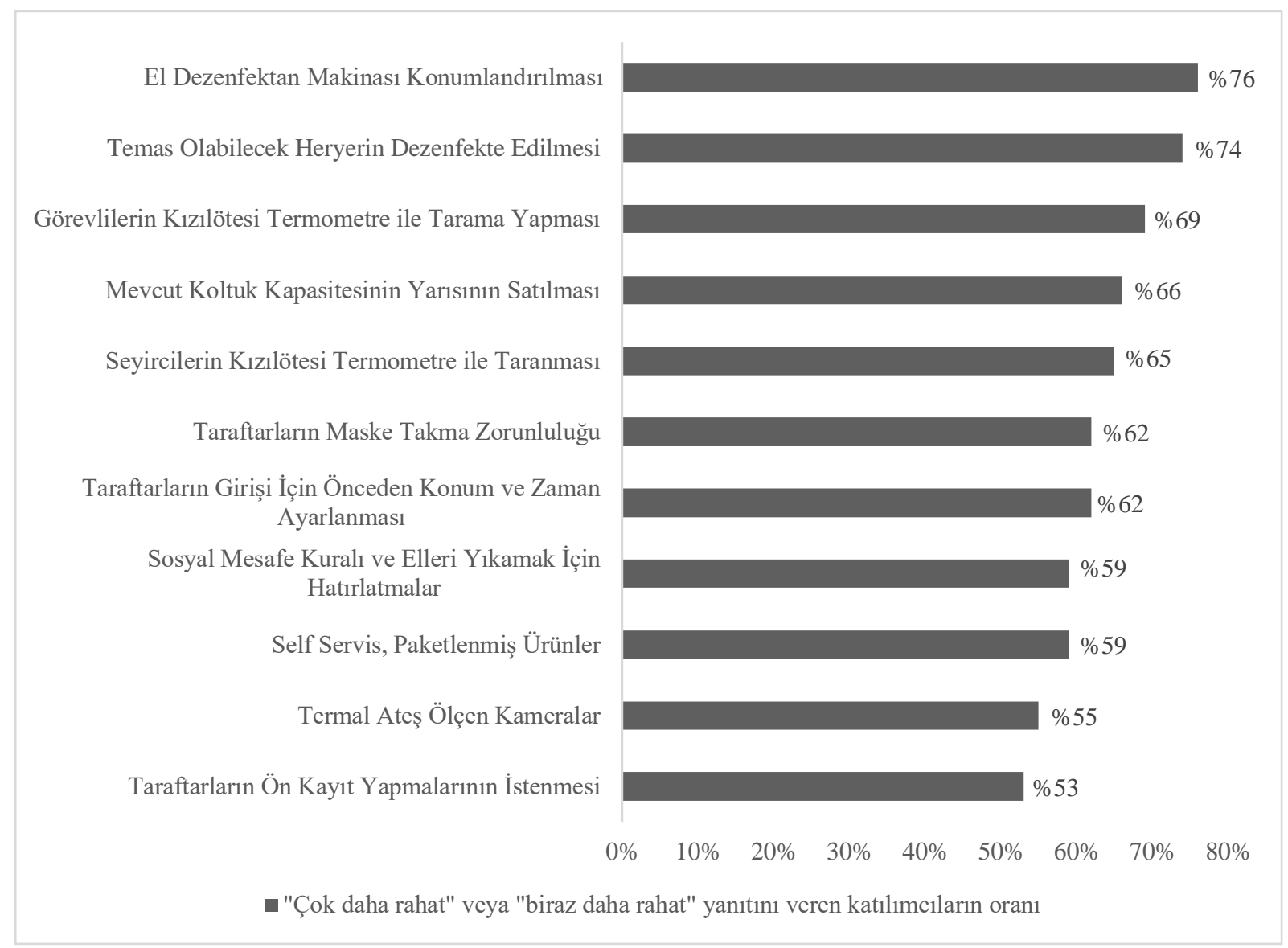

Kaynak: (Gough, 2020a)

Sporseverlerin Covid-19 salgını kontrol altına alındıktan ancak tamamen sifirlanmadan, bir spor organizasyonuna katılıma olasılı̆̆ını arttırmaya yönelik önlemlerin araştırıldığı ankette, katılımcıların yaklaşık \%76'sı el dezenfektan makinalarının stadyumların veya salonların önemli noktalarına yerleştirilmiş olması halinde, \%74'ü temas yaşanabilecek her bir noktanın görevlilerce sürekli olarak dezenfektan edilmesi durumunda, \%69'uda spor organizasyonunun yapılacağ 1 yerde görevlilerin kızı̈ötesi termometreler ile tarama yapması şartıyla bir spor organizasyonunu canlı olarak yerinden izleme fikrinin kendilerini daha rahat ve cezbedici olabileceğini belirtmiştir. Yine sporseverler açısından kendilerini güvende hissetmelerini sağlayacak bir diğer önlem, spor müsabakasının yapılacağı yerin toplam koltuk kapasitesinin yarısının doldurulmuş olması dolayısıyla sosyal mesafe kuralının insanların yaşamlarına yerleşmiş olduğunun bir göstergesi durumundadir. 


\section{Sonuç}

Covid-19 salgınının küresel çapta tüm endüstrilerin dinamikleri üzerinde yıkıcı etkileri olduğu söylenmektedir (Nicola ve ark., 2020) ve bu salgın hiç beklenmedik bir şekilde spor dahil toplumun tüm sektörlerinde önemli kısıtlamalara yol açmıştır. Zaman içinde Covid-19 salgınının her ne kadar tam bir tedavisi veya aşısı bulunamamış olsa da salgının ilk günlerdeki hızı kesilmeye başlanmıştır. Bu gelişmede Covid-19 salgını sırasında çok önemli kayıplar yaşayan iş dünyasının tekrar eski günlere dönmek için motivasyonlarını arttırmaktadır. Hiç kuşku yok ki, toplum psikolojisinin kısıtlamalardan dolayı zarar gördüğ̈ bu pandemi döneminde, normalleşme sürecinin başlatılması ve eski yaşamın tam anlamıyla olmasa da yavaş yavaş geri kazanılmasında sporun önemli bir katkısı olacaktır. Spor organizasyonları ve sporcular, mevcut şartlarda antrenmanların yeniden başlamasından, müsabakaların tekrar yapılmasına kadar çok çeşitli durumlara ilişkin karmaşık kararlarla ve uygulamalarla karşı karşıya kalacaktır.

Sporun ve spor organizasyonlarının yeniden başlamasının zamanlaması ile ilgili kararlarda uluslararası alanda Dünya Sağlık Örgütü, ulusal çapta ise Sağlık Bakanlığının ve dolayısıyla hükümet otoritelerine danışılmalı ve onların tavsiyeleri doğrultusunda kararlar alınmalıdır (Hughes ve ark., 2020). Karar verici durumundaki kişiler ve kuruluşlar spor organizasyonlarının tekrar başlatılmasının veya iptal edilmesinin bir risk değerlendirmesini yapmaları gerekmektedir, bu değerlendirme yapılmadan alınan kararların sosyal ve ekonomik sonuçları hem insani hem de finansal olarak çok maliyetli olabilir. Sporun tekrardan normalleşmesi sürecinde spor organizasyonlarını düzenleyecek olan yetkililer başta bu geri dönüşün halk sağlı̆ğını tehlikeye atmamasını sağlamalıdır. Bununla beraber sporcuların ve diğer tüm personelin sağlı̆̆ riske atılmayacağından emin olunmalıdır. Her şeyden önce genel standartlar ve minimum güvenlik düzeyleri spor branşlarına göre (takım veya bireysel) ayrı ayrı gözetilerek belirlenmelidir.

Ancak spor endüstrisi içinde her spor branşının ekonomik gücü aynı olmamasından dolayı, bir ülkenin bile spor organizasyonlarına ilişkin aldığı kararlar farklılık göstermektedir. Örneğin Türkiye'de Basketbol Federasyonu (TBF, 2020) ve Voleybol Federasyonu (TVF, 2020) erteledikleri liglerini Gençlik ve Spor Bakanlığı ile görüsserek ve kulüplerin fikirlerini alarak 2020 yılı yaz dönemindeki tüm organizasyonlarını iptal etmiştir. Ancak aynı ülkedeki diğer bir federasyon olan Futbol Federasyonu (TFF, 2020) ertelemiş oldukları ligleri haziran ayı içerisinde tekrar başlatacakları kararını vermişlerdir. Hiç şüphesiz bu kararda halk sağlığı veya sporcu sağlığı gibi durumların gözetildiği söylense de tüm bunlardan daha fazla sponsor şirketlerin ve diğer ticari ilişkiler ile futbol kulüplerinin ekonomik anlamdaki sağlığının gözetildiği bilinmektedir. Özellikle Türkiye gibi gelirleri düşük olan liglerde kulüplerin en büyük amacı sportif başarıyla birlikte UEFA Şampiyonlar Ligi'ne bir sonraki yıl katılma hakkı elde etmektir. Çünkü oradan gelecek olan katılım parası mevcut düzenin o kulüp için devamı niteliğindedir. Bu sebepten dolayı daha oynanmamış 8 haftası olan bir ligi tescil etmek, futbolu çok seven bir ülke için yeni bir kaos ortamının oluşmasına neden olacaktır. Dolayısıyla Türkiye Futbol Federasyonu almış olduğu bu karar ile halk sağlığını ve sporcu sağlığını ikinci plana atarak bu son 8 haftayı oynatmaya karar vermiştir. Ve bu fikirlerinde o kadar kararlıdırlar ki TFF Başkanı Nihat Özdemir "Lig başladığı zaman takımlarda pozitif vaka çıkarsa pozitif çıkanları ayırarak yolumuza devam edeceğiz" diye açıklamada bulunmuştur (BBC, 2020).

Sonuç olarak Covid-19 salgını tüm dünyada ticari yaşamı derinden sarsmıştır ve spor endüstrisi ve onun tüm paydaşları da Mart 2020'den Mayıs 2020'ye kadarlık bu 3 aylık kısa sürede bile çok büyük finansal zorluklarla yüz yüze gelmişlerdir. Her ne kadar bir an evvel tüm bu durumun tekrar eskisi gibi olması için bir beklenti bulunsa da spor organizasyonlarıyla kitleler halinde müsabakaların izlenmesi, seyahatlerin yapılması vb. sebepler Covid-19 salgınının tekrardan yeni dalga oluşturmasını sağlayacağından halk sağlığı için bir tehdit unsuru oluşturmaktadır. Spor organizasyonların belirli politikalar ve kurallar çerçevesinde başlatılacak olması spor kulüplerine ve 
federasyonlara ekstra maliyetlerde doğuracaktır. Bu sebeple spor endüstrisine tüm devletlerin ve uluslararası konfederasyonların (FIFA, UEFA vb.) biraz daha ekonomik destek sağlayarak ve bu normalleşme sürecinde kulüplerin ve federasyonların üzerinde oluşacak fazladan ekonomik yüklerin bir kısmını üstlenmesi gerekmektedir.

\section{Kaynakça}

Barabasi, A. L. (2015). Network science. Cambridge University Press.

BBC. (2020). Türkiye'de ligler-TFF Başkanı Nihat Özdemir: Takımlarda virüs çıksa dahi, pozitif çıkanları ayırarak yolumuza devam edeceğiz. https://www.bbc.com/turkce/haberler-turkiye52693731

Caner, Z. G., Ünal, M., Apaydın, Z., Dağ, A., Okur, Ş., Kara, E., \& Bildik, C. (2020). COVID-19 hastalığ1 ve ev egzersizlerinin önemi. Journal of Medical Sciences, 1(3), 25-33. https://doi.org/10.46629/jms.2020.1

Clarkson, B. G., Culvin, A., Pope, S., \& Parry, K. D. (2020). Covid-19: Reflections on threat and uncertainty for the future of elite women's football in England. Managing Sport and Leisure, 1-12. https://doi.org/10.1080/23750472.2020.1766377

Evans, A. B., Blackwell, J., Dolan, P., Fahlén, J., Hoekman, R., Lenneis, V., ... \& Wilcock, L. (2020). Sport in the face of the COVID-19 pandemic: towards an agenda for research in the sociology of sport. European Journal for Sport and Society. https://doi.org/10.1080/16138171.2020.1765100

Gough, C. (2020a). COVID-19: measures to increase likelihood of attending sporting events 2020. Statista. https://www.statista.com/statistics/1114764/covid-live-sports-comfort-levelmeasures/

Gough, C. (2020b). COVID-19: milestones to increase likelihood of attending sporting events 2020. Statista. https://www.statista.com/statistics/1114767/covid-live-sports-comfort-levelmilestones/

Gough, C. (2020c). COVID-19: potential transfer value loss for European soccer teams 2020. Statista. https://www.statista.com/statistics/1109339/coronavirus-transfer-loss-soccerteams/

Gough, C. (2020d). COVID-19: sports industry revenue loss 2020. Statista. https://www.statista.com/statistics/1114808/coronavirus-sports-revenue-loss/

Güzel, P., Yildiz, K., Esentas, M., \& Zerengök, D. (2020). "Know-How" to spend time in home isolation during COVID-19; Restrictions and recreational activities. International Journal of $\begin{array}{llll}\text { Psychology and } & \text { Educational }\end{array}$ http://dx.doi.org/10.17220/ijpes.2020.02.011

Hellewell, J., Abbott, S., Gimma, A., Bosse, N. I., Jarvis, C. I., Russell, T. W., Munday, J. D., Kucharski, A. J., Edmunds, W. J., Funk, S., Eggo, R. M., Sun, F., Flasche, S., Quilty, B. J., Davies, N., Liu, Y., Clifford, S., Klepac, P., Jit, M., \& Zandvoort, K. (2020). Feasibility of controlling COVID-19 outbreaks by isolation of cases and contacts. Lancet Global Health, 8(4), 488-496. https://doi.org/10.1016/S2214-109X(20)30074-7

Hughes, D., Saw, R., Perera, N. K. P., Mooney, M., Wallett, A., Cooke, J., Coatsworth, N., \& Broderick, C. (2020). The Australian Institute of Sport Framework for Rebooting Sport in a COVID-19 Environment, Journal of Science and Medicine in Sport. https://doi.org/10.1016/j.jsams.2020.05.004 
Koronavirüs (Covid-19) Salgınının Spor Organizasyonlarına Etkisi ve Sporda Normalleşme... 461

Hui, D. S. I., Azhar, E., Madani, T. A., Ntoumi, F., Kock, R., Dar, O., Ippolito, G., Mchugh, T. D., Memish, Z. A., Drosten, C., Zumla, A., \& Petersen, E. (2020). The continuing 2019-nCoV epidemic threat of novel coronaviruses to global health — The latest 2019 novel coronavirus outbreak in Wuhan, China. International Journal of Infectious Diseases, 91, 264-266. https://doi.org/10.1016/j.ijid.2020.01.009

Lagne, D. (2020). Potential revenue loss of European football leagues due to the coronavirus. Statista. https://www.statista.com/statistics/1105710/potential-revenue-loss-of-major-europefootball-leaguesdue-to-the-coronavirus-covid-19-by-source/

Memish, Z. A., Steffen, R., White, P., Dar, O., Azhar, E. I., Sharma, A., \& Zumla, A. (2019). Mass gatherings medicine: Public health issues arising from mass gathering religious and sporting events. The Lancet, 393(10185), 2073-2084. https://doi.org/10.1016/S0140-6736(19)30501$\mathrm{X}$

Millán-Oñate, J., Rodriguez-Morales, A. J., Camacho-Moreno, G., Mendoza-Ramírez, H., Rodríguez-Sabogal, I. A., \& Álvarez-Moreno, C. (2020). A new emerging zoonotic virus of concern: the 2019 novel Coronavirus (SARS CoV-2). Infectio, 24(3), 187-192. http://doi.org/10.22354/in.v24i3.848

Nicola, M., Alsafi, Z., Sohrabi, C., Kerwan, A., Al-Jabir, A., Iosifidis, C., Agha, M., \& Agha, R. (2020). The Socio-Economic Implications of the Coronavirus and COVID-19 Pandemic: A Review. International Journal of Surgery. https://doi.org/10.1016/j.ijsu.2020.04.018

Nishiura, H., Kobayashi, T., Yang, Y., Hayashi, K., Miyama, T., Kinoshita, R., Linton, N. M., Jung, S. M., Yuan, B., Suzuki, A., \& Akhmetzhanov, A. R. (2020). The Rate of Underascertainment of Novel Coronavirus (2019-nCoV) Infection: Estimation Using Japanese Passengers Data on Evacuation Flights. J. Clin. Med. 9, 419. https://doi.org/10.3390/jcm9020419

Parnell, D., Widdop, P., Bond, A., \& Wilson, R. (2020). COVID-19, networks and sport. Managing Sport and Leisure, 1-7 https://doi.org/10.1080/23750472.2020.1750100

Rodríguez-Morales, A. J., MacGregor, K., Kanagarajah, S., Patel, D., \& Schlagenhauf, P. (2020). Going global-Travel and the 2019 novel coronavirus. Travel medicine and infectious disease, 33, 101578. https://doi.org/10.1016/j.tmaid.2020.101578

Shigemura, J., Ursano, R. J., Morganstein, J. C., Kurosawa, M., \& Benedek, D. M. (2020). Public responses to the novel 2019 coronavirus $(2019-\mathrm{nCoV})$ in Japan: mental health consequences and target populations. Psychiatry and clinical neurosciences, 74(4), 281. https://doi.org/10.1111/pcn.12988

Stevens, V., Prins, R. G. (2020). "Twitterers' sentiments towards the COVID-19 responses of the FIA, UEFA and IOC." Retrieved April 24, 2020 from https://www.mulierinstituut.nl/publicaties/25341/twitterers-sentimentstowards-the-covid19-responses-of-the-fia-uefa-and-ioc/

TBF. (2020). Bilgilendirme. https://www.tbf.org.tr/haber/bilgilendirme-11052020

TFF. (2020a). Koronavirüs (Kovid-19) tedbirleri ve seyircisiz oynanacak maçlar hakkında. https://www.tff.org/default.aspx?pageID=687\&ftxtID=33152

TFF. (2020b). TFF Yönetim $\quad$ Kurulu https://www.tff.org/default.aspx?pageID=687\&ftxtID=33276 
Türkmen, M. \& Özsarı, A. (2020). Covid-19 Salgını ve Spor Sektörüne Etkileri. International Journal of Sport Culture and Science, 8(2), 55-67. https://doi.org/10.14486/IntJSCS.2020.596

TVF. (2020). Kamuoyu Duyurusu. https://www.tvf.org.tr/duyurular/kamuoyu-duyurusu-4/

UEFA. (2020). COVID-19: latest updates on UEFA competitions. Erişim Tarihi: 26.05.2020. https://www.uefa.com/insideuefa/about-uefa/news/newsid=2641065.html

Wang, C., Horby, P. W., Hayden, F. G., \& Gao, G. F. (2020). A novel coronavirus outbreak of global health concern. The Lancet, 395(10223), 470-473. https://doi.org/10.1016/S01406736(20)30185-9

World Health Organisation. (2020a). Joint ICAO-WHO Statement on COVID-19. https://www.icao.int/Security/COVID-19/Pages/Statements.aspx

World Health Organisation. (2020b). Key planning recommendations for Mass Gatherings in the context of the current COVID-19 outbreak. https://www.who.int/publicationsdetail/keyplanning-recommendations-for-mass-gatheringsin-the-context-of-the-currentcovid-19-outbreak

World Health Organisation. (2020c) Novel Coronavirus - China. 202012 January; https://www.who.int/csr/don/12-january-2020-novel-coronavirus-china/en/

World Health Organization. (2011). WHO Global mass gatherings: implications and opportunities for global health security. https://apps.who.int/iris/handle/10665/23751 